\title{
On the Enlightenment of Teaching Communication on Building Decoration Engineering Major
}

\author{
Aimin Wei \\ School of Architectural Engineering of GZCCC, Guangzhou 510925, China
}

\begin{abstract}
With the increase of current employment pressure, it has become the development concept of the school to serve the development of students' career. It is a key factor in mastering communication skills with people whether a student can achieve employment. In fact, the teaching content is the core of classroom teaching, and teaching communication is the main carrier for the implementation of teaching content. Through the analysis of the status at home and abroad, the improvement measures in the teaching process of architectural decoration engineering is put forward in this paper.
\end{abstract}

Keywords: Teaching communication; Architectural decoration engineering; Teaching; enlightenment

\section{论教学沟通对建筑装饰工程技术专业教学的启示}

\author{
魏爱敏 \\ (广州城建职业学院, 广东广州 510925 )
}

摘要: 随着当前就业压力的增大,为学生职业生涯发展服务已经成为学校的发展理念。学生能否实现就业的关键因素在 于是否掌握与人的沟通技巧。事实上, 教学内容是课堂教学的核心, 教学沟通是教学内容实施的主要载体。本文通过对国内 外现状的分析, 提出在建筑装饰工程技术专业教学过程中改进措施。

关键词: 教学沟通; 建筑装饰工程技术; 教学; 启示

\section{引言}

本人有幸参加了 2016 年留学基金委为期半年的“德国高等教育教学法出国研修项目”, 对德国职业教育 有了较为全面的了解。德国的职业教育经验有很多值得我们学习的地方, 例如它的“双元制”职业教育模式、 教学模式、校企合作模式、职业教育的法律法规、师资队伍建设、教学考核质量保障制度等。

作为一名长期在一线工作的专业教师，如果能够把本次学到的德国的课程设置、教学内容设计与沟通 技巧等方面经验应用到实际的教学中去, 将是自己能够真正去落实与执行的工作任务, 并使学生获益。事 实上, 教学内容是课堂教学的核心, 教学沟通是教学内容实施的主要载体。实施有效的教学内容和进行顺 畅的沟通, 将有利于提高人才培养效率和质量。国内的高职院校在教学内容和沟通上存在着一些问题, 这 些制约了职业教育向更高层次发展。

\section{1 国内现状}

\section{1 教学内容现状}

我国从 20 世纪 90 年代末开始接触项目教学, 关于项目教学法的研究内容主要集中于以下几个方面: (1) 是关于项目教学法的内涵、特点及教学原则等方面的研究; (2) 关于项目教学法在某一专业的具体 应用研究; (3) 关于项目教学法的课程建设的研究; (4) 关于项目教学法的评价指标体系研究。 
通过调研建筑装饰工程技术专业的日常教学, 发现比较普遍地存在着为了项目教学法而项目教学法的 形式主义现象; 部分教师虽然也知道项目教学的重要性，但并未能在课程内容设计上真正地去实施项目教 学。具体来说, 在我们的教学方面, 存在以下的内容问题: (1) 教学内容陈旧, 较少更新; (2) 教学内 容来源单一, 主要是集中在某本教程; （3）教学内容的范围, 深度等方面随意性较大, 由授课老师决定, 没有标准; (4) 教学内容的设计, 未能充分考虑学习对象的需求; (5) 教学内容偏向于课程技术内容方 面的讲解，未考虑学生的其他素质方面能力的培养，例如：沟通与交流能力;

建筑装饰工程技术专业教育课程开发大部份是将理论基础课程和专业课程分开, 这虽然给学生提供了 比较牢固的理论基础, 但由于其理论与实践并非同时进行, 而是先理论后实践, 这就导致学生在头脑中没 有实践的概念, 理论学习没有很大的效果, 只是死记硬背。等到实践的时候, 又因为理论学习不扎实, 无 法将所学到的理论知识内容应用到实践中, 理论和实践的匹配程度很差。

此外, 发现本专业课程的体系设计较为混乱。课程体系长期无变化, 依旧按照计算机专业基础课、专 业课、公共课程安排教学。部分院校为了追求校企合作, 片面地听从企业人员建议, 未经过科学论证就少 开、增开、乱开课程, 对课程名称、学时、课程标准随意变更, 使得课程体系混乱。同时为了片面地强调 工学结合，未经过系统化设计便匀匀实施，使得教学目标难以实现，未能取得预期效果。

\section{2 沟通模式现状}

沟通是一种至关重要的教育方式，是教育实现的基石。教育活动得以有效实现是师生双方良好沟通的 结果, 所以教育离不开沟通。职业教育作为教育中特殊的一类, 师生沟通问题尤显重要。职业教育中师生 沟通存在着一些问题与障碍，这妨碍了师生间的沟通交流效果，具体来说存在以下问题：

(1) 以教师为中心, 缺乏小组讨论, 对学生的提问不足, 较少根据学生的回答来进行针对性的讨论; （2）师生、教师和学校管理层之间的沟通途径和沟通方式较为单一, 未能达到有效地沟通; （3）师生交 往接触少, 关系淡漠; 师生除课堂教学交往外, 课后各自行走匀匀, 碰面也不互打招呼, 感情沟通渠道呈 现明显的萎缩趋势; （4）师生间沟通的位差效应及本位主义严重, 师生因地位、角色、认知及经验水平 的差距等的不同造成师生间的不平等地位, 造成教师难以以平等心态与学生平等对话, 缺乏平行沟通与双 向沟通, 而往往是习惯于单向沟通。师生间的本位主义交流易强加别人, 缺乏宽容, 易于产生抵触、抗拒 和排斥心理，拉大师生间情感上的距离，影响师生关系发展，故而严重影响沟通的顺利进行。

\section{2 德国经验}

以学生为中心是现代国际职教的一个重要理念, 在欧美等国广为流传。对于 21 世纪中国国内的职业 教育来说，树立“以学生为中心”的教育思想具有特别重要的意义。

德国教育注重学习者的参与, 无论是教学内容的讲授、教学活动的组织还是教学效果的评价, 都积极 引导学习者参与其中。采用“行为导向理论”, 强调“创造出师生互动的社会交往的仿真情境”, 采用以学生为 中心的教学方法, 诸如项目教学法、模拟教学法和角色扮演法等从学习者的角度来看, 效果远远好于只是 单纯听课的方式; 此外, 教学的顺畅沟通不限于师生之间的沟通, 还有教师和学校管理层的顺畅沟通。

德国职业学校的班级人数约为 20 人左右, 为典型的小班化的教学场所。小班化教学首先为学生创造 了更多的实际操作机会, 师生之间的沟通交流的机会也更多, 教师与学生的交流点拨的过程可以让学生更 好、更快地懂得专业知识。 
行动导向教学法是德国职业教育的主要教学方法, 它打破了学科体系的框架, 构建了教学行动体系。 行动导向教学的基本意义在于: 学生是学习过程的中心, 主动性非常强, 教师是学习过程的组织者与协调 人, 遵循“信息、计划、决策、实施、检查、评估”这一完整的“行动”序列, 即: 教师在授课时提供学习的相 关信息, 学生根据教师所提供的信息进行计划, 在教师帮助下进行决策、实施、检查, 然后小组进行评估, 教师也对学生进行评估, 并反馈检查、评估内容, 从而促进教学与学习。在教学中, 教师与学生互动, 让 学生通过“独立地获取信息、独立地制订计划、独立地实施计划、独立地评估计划”, 在自己动手的实践中, 掌握职业技能、习得专业知识, 从而构建属于自己的经验和知识体系, 并从中培养学生的专业能力、人格 能力、社会能力、方法能力、沟通能力、学习能力。学生始终在前台, 教师在后台, 教师只是学生的咨询 者与引路人。

为了实现有效的教学沟通, 教师的任教能力也要有相应的要求:

(1) 在对教师的任教能力要求上, 应该具备激发学生学习积极性的能力;

(2) 在对教师的任教能力要求上, 应该具备促进学生自主学习的能力;

M. Köhler 老师在讲解 Communication 时, 在课堂上进行了练习, 选择了 20 位老师, 分别抽签拥有 不同的身份, 在一艘只能承载 2 人的小船上, 通过沟通（或者争论）的方式决定谁留下或者离开。通过谁 应该留在船上这个讨论话题，引出讨论的方法，最后以一个讨论例子为例，给出了讨论的几个典型应用方 法。游戏在参与者的激烈讨论中圆满完成，教师对游戏的过程进行了点评和总结。

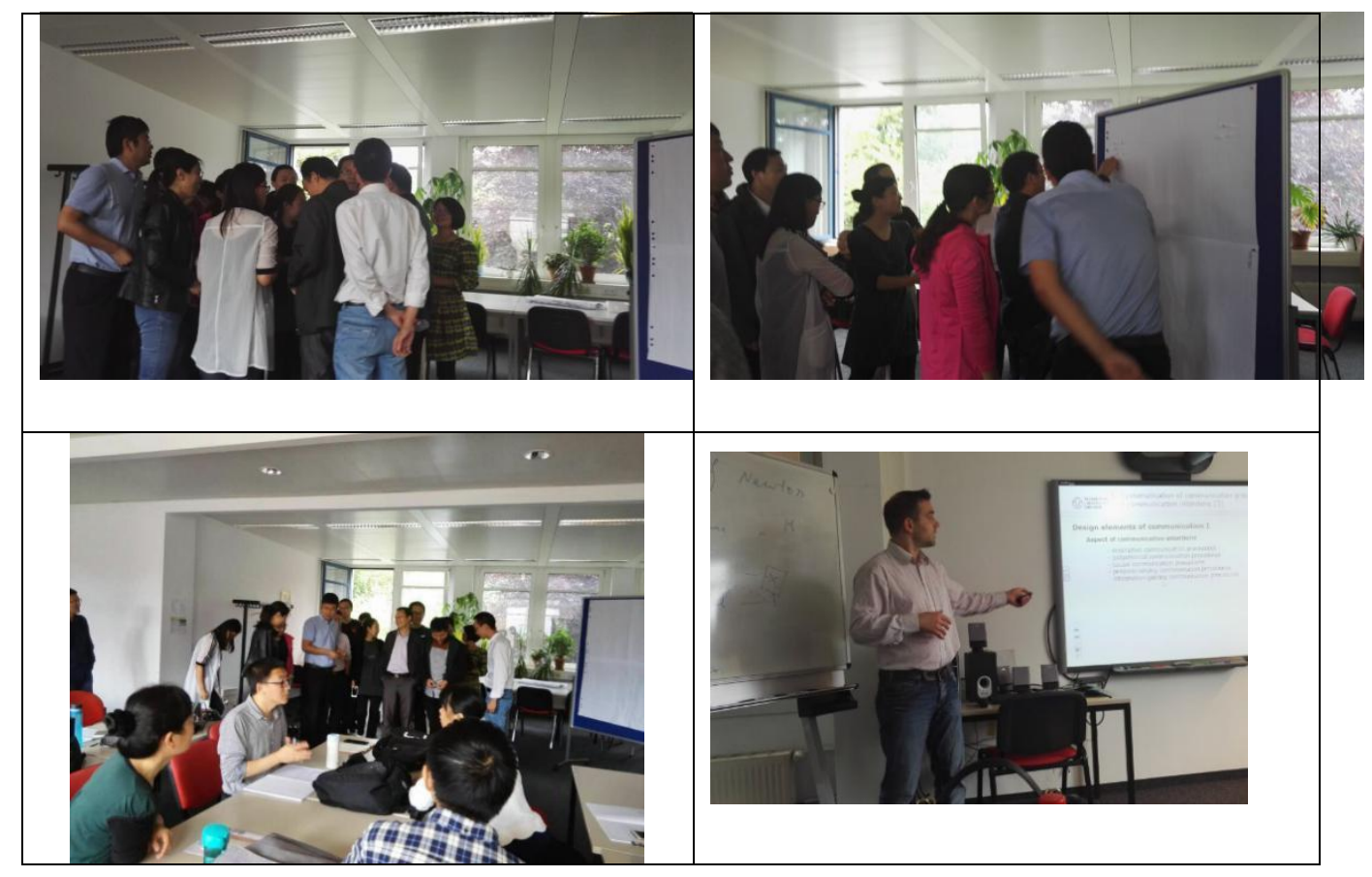

通过 M. Köhler 老师的课堂的学习, 我们有以下几点的反思:

(1) 课堂上, 老师通过学员上讲台讲课, 分析学员在讲课过程中存在的问题, 通过反复指导, 使学 员的水平得到了提高。

(2) Communication 在教学中非常重要, 是学习者和教学者之间信息传递的重要方式, 也是作为教 师必须具备的基本功。本次课让我们在实际参与中深刻领会到了在教学过程中沟通的必要性和有效方式。

（3）老师总体介绍交流中的设计元素的基础上，重点介绍了一个好的 discussion 的特征，以及对话 
性沟通过程"argumentation"的类型、过程结构、进行模式和策略。使我印象比较深刻的是对话中的过程结 构, 比如：提问回答链，可能以前上课都无意识的使用过，但并没有上升到“沟通”的高度，在以后的教学 设计中要有意识的加入“沟通设计”, 确保课堂“以学生为主体”取得更好的教学效果! 再比如, discussion 可 能上课都组织过, 但什么是一个好的 discussion 并没有好好思考过, “清晰的目标、实践问题、好的引导、 适时的推动、提问的技术和好的反馈”都考虑到可以让讨论更具效果！

\section{3 改进措施}

在师生关系复杂的今天, 尊重学生在师生沟通中是非常重要的, 只有尊重对方, 才能得到对方的尊重, 对方才会愿意打开沟通之门, 愿意与我们坦诚沟通, 尊重学生是打开与学生沟通的金钥匙。为此, 我们可 以从以下几方面进行改改革:

（1）提高教师的沟通能力和对此的重视程度, 在以后的教学设计中要有意识的加入“沟通设计”, 确保 课堂“以学生为主体”取得更好的教学效果。“清晰的目标、实践问题、好的引导、适时的推动、提问的技术 和好的反馈”都考虑到可以让讨论更具效果。

(2) 建立以学生为中心的教学模式, 是用多种方式执行 KOLB 循环（见图 1)，给学生以经验 $\rightarrow$ 学 生回顾、反思 $\rightarrow$ 得出结论 $\rightarrow$ 改进后计划下一步 $\rightarrow$ 重新试验 $\rightarrow$ 再取得经验一直循环下去。教师不是知识灌输, 而是行为的指导或咨询; 教学方法不是单向灌输, 而是双向地传递和互动。

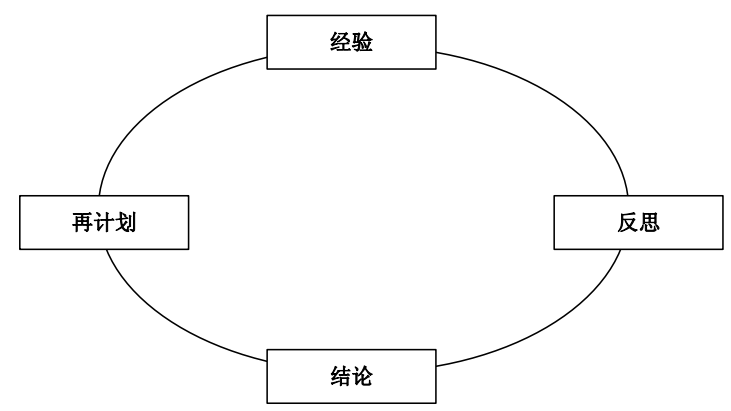

图 1

（3）完善师生沟通的机制，“以人为本”，有效地尊重学生个性，使得其更为顺畅。

\section{4 总结}

在教学过程中, 课堂组织与教学形式要讲求多样化的方式, 增加课堂教学的高效性让同学们自主的去 学习, 利用课下的时间收集资料, 课上进行演示, 提高学习的效率, 实行分组教学的教学方式同时强化实 施规范的管理制度, 编写课程标准、教学任务、课件以及教学任务书等教学文件以此来高校的完成教学任 务, 同学们通过分组学习, 同学之间相互交流在完成学习任务的同时有效地提升了学生在人际交往上的沟 通技巧和沟通能力。改变原来的以教师为主导, 让学生成为主导, 而教师起到引导监督的作用, 学生通过 自主学习的方式, 激发了学习的兴趣和创造力, 同时增加了学生的沟通能力, 在遇到问题时, 通过同学之 间的相互交流, 在获得知识的同时提高了自己的沟通能力。选择自由平等的沟通交流环境, 在其中营造出 双方之间坦诚信赖的沟通氛围进行真正的交流。高质量的沟通以平等为前提，平等的交流沟通有利于良好 沟通氛围的建立。良好的沟通必须是双向的, 这样才能增近师生之间关系, 同学之间的相处才能更加愉快。 为同学们营造了一个良好的沟通氛围, 同学们就会不由自主的融入其中, 自身的沟通能力在潜移默化中提 到提高。 


\section{5 致谢}

本文系国家留学基金委“2016 年高等教育教学法出国研修项目”（项目编号：留金发 [2016] 5054） 资助, 广州城建职业学院 2016-2017 学年立项重点课题 “建筑装饰工程技术专业适应珠三角经济发展的 研究”的研究成果之一。（课题编号：Z201601）

\section{Acknowledge}

This article is supported by the National Study Abroad Fund "2016 Higher Education Teaching Law to study abroad project" (project number: stay blonde [2016] 5054), one of the research results of Guangzhou Urban Construction Vocational College 2016-2017 Academic Year key project "architectural decoration engineering technology to adapt to the Pearl River Delta Economic development research ". (Project number: Z201601)

\section{参考文献:}

[1]关丽丽, 景东芝. 高职沟通技巧课程教学实践 [J]. 当代教育实践与教学研究, 2016, (06) :190-191.

[2]时文清. 高职院校口才艺术与人际沟通课程教学方法探讨 [J]. 才智, 2016, (09) :41.

[3] 黄健. 基于全人教育理念的高职 “职业沟通” 课程教学探索 [J]. 凯里学院学报, 2015, (05) : 148-151.

[4] 吴颖. 高职学生沟通能力培养课程教学改革探索 [J]. 浙江纺织服装职业技术学院学报, 2015, (03): 92-96.

[5]秦汝芳, 王宏. 网络环境下高职《人际沟通》课程教学改革实践研究 [J]. 科技资讯, 2016, (19) : 122-123.

[6]布丽榛, 秦汝芳. 基于网络的高职《人际沟通》教学改革 $[J]$. 科技资讯, 2016, (25) :94+96.

[7] 焚翠娟, 李志军. 工学结合下高职课堂实训教学设计探讨与实践—— 《管理沟通实务》为例 $[\mathrm{J}]$. 南方职业教育学 刊, 2015, (01):55-59.

[8]邓先丽. 高职院校沟通课程能力训练教学模式初探 [J]. 教育教学论坛, 2014, (42) : 250-252.

[9]张露尹. 高职院校《沟通技巧》课程教学改革探究 [J]. 求知导刊, 2014, (05) : 148 .

[10]李鸿. 高职职业沟通课参与式教学探析 [J]. 中国成人教育, 2013, (16):152-153.

[11] 姜平平, 代亚松. 高职院校管理沟通课程教学方法的应用研究 [J]. 高等函授学报 (自然科学 版), 2013, (01):77-78+81.

[12] 贾凝. 高职《沟通技巧》课程实践教学体系探索与研究 [J]. 科技信息, 2009, (16) :538-539.

地址: 广州从化环市东路 166 号广州城建职业学院建筑工程学院 魏爱敏收

电话：13925119162

作者简介:

魏爱敏，女，生于 1977 年，广东人，讲师，工艺美术师，主要研究方向为建筑经济及高职教学管理。

\section{References:}

[1] Guan Lili, Jing Dongzhi. Education Practice on the Interpersonal Communication Course in Higher Vocational Colleges [J] Contemporary Education Practice and Teaching Research, 2016, (06): 190-191. (Philosophy and Social Sciences Edition) "2009-01 [J].

[2] Shi Wenqing. A Study on the Teaching Method of Eloquence Art and Interpersonal Communication Course in Higher Vocational Colleges [J]. Intelligence, 2016, (09): 41.

[3] Huang Jian. Teaching Exploration of "Vocational Communication" Curriculum Based on the Concept of Holistic Education [J]. Journal of Carey College, 2015, (05): 148-151.

[4] Wu Ying. Teaching Reform Exploration of the Curriculum Cultivating Higher Vocational College Students' Communication Ability [J]. Journal of Zhejiang Textile and Apparel Vocational and Technical College, 2015, (03): 92-96. 
[5] Qin Rufang, Wang Hong. Study on the Higher Vocational College "Interpersonal Communication" Teaching Reform Practice under Network Environment [J]. Science and Technology Information, 2016, (19): 122-123.

[6] Bu Lizhen, Qin Rufang. Higher Vocational College “Interpersonal Communication” Teaching Reform Based on Network [J]. Science and Technology Information, 2016, (25): $94+96$.

[7] Fan Cui-juan, Li Zhijun. Study and Practice of Practical Teaching Design in Higher Vocational Education Based on Combination of Work and Study - Taking "Management Communication Practice" as an Example [J]. Journal of Southern Vocational Education, 2015, (01): 55-59.

[8] Deng Xianli. First Exploration of Higher Vocational College Communication Curriculum Ability Training Teaching Model [J]. Education and Teaching Forum, 2014, (42): 250-252.

[9] Zhang Luyin. Study on Higher Vocational Colleges “Communication Skills" Teaching Reform [J]. Guide of Seeking Knowledge, 2014, (05): 148.

[10]Li Hong. Participatory Teaching Analysis of Higher Vocational Communication Class [J]. China Adult Education, 2013, (16): 152-153.

[11]Jiang Pingping, Dai Yasong. Applied Study on the Teaching Method of High Vocational Colleges Management and Communication Curriculum [J]. Academic Journal of Higher Correspondence (Natural Science Version), 2013, (01):77-78+81.

[12]Jia Ning. Exploration and Study on Higher Vocational College "Communication Skills" Curriculum Teaching Practice [J]. Science Information, 2009, (16):538-539.

Address: School of Architectural Engineering of GZCCC, No. 166, East Huanshi Road, Conghua, Guangzhou, recipient: WEI Aimin

Telephone: 13925119162

WEI Aimin, female, born in 1977 in Guangdong Province, lecturer, craft artistic, main research direction: architecture economics and vocational college teaching management 